\title{
Inovação do lado de cá: uma experiência de ciência e tecnologia em gestão na Amazônia setentrional oriental
}

\section{Daniel Chaves ${ }^{1}$ e Vitor Hugo Santis Costa ${ }^{2}$}

1 Doutor em História Comparada pelo Programa de Pós-Graduação em História Comparada da UFRJ. Professor Adjunto da Universidade Federal do Amapá, no Programa de Pós-Graduação em Mestrado em Desenvolvimento Regional e no Programa de PósGraduação em Estudos de Fronteira, Brasil. E-mail: daniel.chaves@unifap.br e daniel.s.chaves@gmail.com

2 Graduando em Direito na Universidade Federal do Amapá. Pesquisador júnior (bolsista de Iniciação Científica) do Núcleo de Inovação e Transferência de Tecnologia da Universidade Federal do Amapá. E-mail: vhs.1994@gmail.com

RESUMO: Este texto pretende, em um panorama conciso porém abrangente e aberto, apresentar a experiência da gestão da propriedade intelectual na Universidade Federal do Amapá, por meio do seu Núcleo de Inovação e Transferência de Tecnologia (NITT/Unifap), ao longo de um período recortado de 18 meses de atuação. A ênfase se dará sobre como prospectou-se, em termos institucionais, uma estratégia de arranque acadêmico na direção da ampliação dos canais de registro da propriedade intelectual, por um lado, e por outro, no sentido dos caminhos futuros os quais tal Núcleo pode, como agência de desenvolvimento, articular ações próInovação e Transferência de Tecnologia e Conhecimento de forma ainda mais intensa, atualizando-se perante novas normativas legais.

Palavras-Chave: Inovação; Transferência de Tecnologia; Gestão; Propriedade Intelectual; Amazônia

Innovation on the other side: a scientific-technological management experience in northeastern Amazon river basin

ABSTRACT: This text intends, in a concise but comprehensive and open panorama, to present the management of intellectual property experience at the Federal University of Amapá, through its Innovation and Technology Transfer Centre, over a period of time of 18 months of performance. The emphasis will be on how, in institutional terms, an academic catch-up strategy has been pursued in the direction of the expansion of intellectual property registration channels, on the one hand, and on the other in the direction of the future paths which such a Centre can, as a development agency, to articulate pro-Innovation and Technology and Knowledge Transfer activities even more intensely, updating itself before new legal regulations.

Palavras-chave: Innovation; Technlogy Transfer; Management; Intelectual Property; Amazon

\section{APRESENTAÇÃO: DO PONTO ONDE PAR- TIMOS}

Pretendemos, nesta abordagem textual, delinear concisamente - ainda que reconheçamos o caráter holístico e totalizante da discussão - a experiência da gestão da propriedade intelectual na Universidade Federal do Amapá, por meio do seu Núcleo de Inovação e Transferência de Tecnologia (NITT/Unifap), ao longo de um período recortado de 18 meses de atuação. Nossa ênfase se dará sobre como se prospectou, em termos institucionais, uma estratégia de arranque acadêmico na direção da ampliação dos canais de registro da propriedade intelectual, por um lado, e por outro, no sentido dos caminhos futuros os quais tal 
Núcleo pode, como agência de desenvolvimento, articular ações pró-Inovação e Transferência de Tecnologia e Conhecimento de forma ainda mais intensa, atualizando-se perante novas normativas legais.

Trata-se, portanto, de um texto que está no limite entre um balanço de gestão e uma reflexão acadêmica, em uma convergência estruturante estratégica. Nesse sentido, para fins de construção de plataforma de gestão, de legislatura e de ampla penetração do ambiente socialmente referenciado no qual a Universidade se insere, em 360, há de se reconhecer, primordialmente, a sua matriz participativa e inclusiva, voltada para as necessidades do estado do Amapá e suas forças produtivas, sua base científicotecnológica e sua governança institucionalizada e associativa. Podemos determinar que, voltados para o processo de construção de agendas de pesquisa integradas às necessidades sociais e produtivas, há quatro pilares essenciais para um debate efetivamente voltado para o desenvolvimento regional integrado: sustentabilidade produtiva, administração inteligente, contas transparentes e pluralidade participativa na tomada de decisão. Há de se observar, com foco no respeito e percepção totalizantes sobre as culturas, os processos históricos, os modos de agir-político e as necessidades reais do estado e suas mesorregionalidades, que o processo de Inovação e Transferência de Tecnologia no Amapá não deve ser algo absoluto obediente ou idêntico a outros padrões de desenvolvimento regional. Para constituir-se tal construção eficiente e ao mesmo tempo reflexiva-compreensiva, nota-se o imperativo amazônico-caribenho, a imponderável biodiversidade tropical amapaense, a localização em múltiplas fronteiras geopolíticas, climáticas e etno- raciais/culturais, as reservas produtivas ainda existentes no estado, e não menos importante, o complexo e heterogêneo processo de construção de um tecido social baseado em migrações - e portanto, em busca por oportunidades para a PanAmazônia. Estes devem ser elementos doutrinários para plataformas que demonstrem como a Ciência e a Tecnologia, para o beneficiamento da sociedade amapaense, devem ser inequivocamente voltadas para a transferência da tecnologia e do conhecimento como formas de ampliar oportunidades, popularizar ciência e constituir tecnologias originais e inéditas no nosso espaço geográfico.

Com foco no imprescindível mapeamento, no essencial incentivo e no propositivo diálogo entre os diversos atores (Instituições de Ciência e Tecnologia, Instituições de Ensino Superior, como educação e ciência e tecnologia; Governos Estadual \& Municipais, Cortes e Tribunais de Justiça e Legisladores/as, como poder público; Médias, Pequenas e Micro Empresas como iniciativa privada) interessados no debate e intervenção sobre empreendedorismo inovador e transferência de tecnologia no Amapá, a Universidade Federal do Amapá tem se proposto a observar as pedrasfundamentais de sistemáticos esforços nacionais na área de Inovação e Transferência de Tecnologia em recensear, interagir e adensar nestas dimensões, voltando-se para o fortalecimento do ecossistema de inovação e tecnologia do Amapá através do ambiente da Unifap, contando com a colaboração de seus parceiros. Consideramos possível apontar, no âmbito das atividades regularmente concentradas no Núcleo de Inovação e Transferência de Tecnologia da Unifap (NITT/Unifap), o destacado papel da Uni- 
versidade no incremento dos seus coeficientes de desempenho diante dos desafios da proteção da propriedade intelectual conforme reconhecida nas categorias da instância soberana do Instituto Nacional da Propriedade Industrial (INPI), como patentes, softwares, modelos de utilidade, marcas e indicações geográficas; contudo, destacamos que o desafio da transferência da tecnologia como processo, desde a base da construção local/regional das agendas de pesquisa, está sendo diretamente influenciado pelo demandante momento de mudanças decorrentes de uma profunda revolução tecno-científica - para alguns, uma Quarta Revolução Industrial, fortemente calcada na informação, na virtualização, na pulverização e na automação - tem alterado significativamente o relevo e as tessituras do diálogo entre pesquisa pura e pesquisa aplicada no ambiente acadêmico global. Tal contexto, nesse sentido, espelhando nossa visão sobre a Inovação, precisa ser esmiuçado.

Tais mudanças, em larga medida decorrentes da introdução de fatores como automação algorítimica, interoperabilidade na gestão de dados massivos, arquitetura da informação em redes virtuais, entre outros, tem imposto xeque a categorias e estruturas que pareciam imprescindíveis ao sistema social do modus operandi da ciência e tecnologia. A inovação não se apresenta mais apenas como tradicionalmente mantenedora do aperfeiçoamento das cadeias e perpetuação dos modos de produção, mas sim empoderada de uma ação disruptiva cada vez mais constante e voraz. As emergentes startups, iniciativas empreendedoras de baixo custo, equipe reduzida e inovadora, voltadas para o crescimento rápido de um produto, processo ou serviço inovador, partindo de um modelo de produção/negócios repetível (ou seja, passível de ser reproduzido com agilidade sem delongadas customizações) e escalável (ou seja, de potencialmente acomodar crescimento em escala) porém incerto, proliferam-se como formas de vida dos ecossistemas de inovação, então em constante mutação. Esta potência pode moldar para aprimorar e construir, ou destrutivamente lançar ao desuso estruturas de sistemas produtivos tidos como perenes, pulverizando em poucos ciclos toda sorte de mercados, serviços e produtos e afetando cadeias produtivas que em ambiente globalizado podem potencializar oportunidades ou liquidar vantagens competitivas. Estas situações históricas e regionais nas quais o Amapá e a Unifap, por conseguinte, encontram-se, precisam reposicionar-se objetivamente e tomar o momento como onda a se somar, consciente das suas necessidades provinciais, deve-se ressaltar ponderadamente. Em outras palavras, o que é risco aos estabelecidos do status quo também é oportunidade para concorrentes periféricos se reposicionarem.

Para além do desenvolvimento aplicado de técnicas científicas voltadas para a produção ou extração de riquezas como processo global que pode incidir positivamente, orbi et urbi, nas regiões e suas províncias, a reformatação da contemporaneidade desfralda-se pari passu à dimensão dos problemas simultâneos e globais do industrialismo clássico mantido pela governança calcada nas instituições públicas e seus parceiros privados, com forte impacto sobre recursos naturais, humanos e culturais. Crises geradas por problemas como desemprego e retração dos produtos internos brutos, defasagem de infraestrutura logística interurbana, pressões demográficas, transi- 
ções contra-patriarcais e crises climáticoambientais, que rapidamente são noticiadas, debatidas e condensadas na opinião pública crítica, seja em telejornais, rádio ou redes sociais, e determinam a pauta destas instituições, porosas ou não a este criticismo público. Qual o potencial para que a crise seja oportunidade, indubitavelmente, é determinado pelo comportamento dos gestores e moderadores dos fluxos. Os problemas da soberania da esfera pública a qual uma Universidade Federal faz parte por excelência, zelada pelas instituições responsáveis, mas pautadas pelo interesse civil generalizado por um lado, por outro se encontram com a premissa do Desenvolvimento como racionalidade de superação das condições que, regionalmente específicas, encontram-se dispostas no Amapá e na Amazônia, sendo ainda carentes em inumeráveis aspectos. Ainda em outras palavras, 0 que não for articulado inclusivamente como exercício de promoção da participação coletiva na esfera pública, seguramente se tornará empecilho para quaisquer governanças.

É possível dizer que dentre os propósitos das ações para a promoção e gestão da Inovação e Transferência de Tecnologia na Unifap, o primordial intuito é o de criar condições práticas e pedagógicas de promoção da criatividade no ambiente gerador de soluções inovativas - práticas, processos, serviços ou produtos - que é a Universidade. Esta instrumentalização propositiva, com o devido respeito à autoralidade e ao princípio da liberdade criativa, das ideias produzidas no interior dos seus grupos, laboratórios, colegiados, projetos, centros, programas de pós-graduação e departamentos, que tenham por sua vez a capacidade de arrolar estas inovações no sentido de me-
Ihorar a Universidade, culminariam na potencialização do papel da Universidade na direção de uma agência de desenvolvimento estadual e regional, prospectiva e inteligente.

Constata-se que cresceu em importância a prospecção tecnológica e inteligência competitiva, e que estudar cenários futuros e vislumbrar possíveis nichos de atuação e mudanças de trajetória tecnológica é tarefa para cada setor que a ICT pretendem introduzir produtos ou processos competitivos. O abraço à inovação, aceitando a celeridade dos tempos e a multiplicidade crescente de demandas promove a inovação a um nível prioritário, essencial e estruturalmente constitutivo para o provimento de soluções seguras desde a base do processo criativo até as mais variadas dimensões institucionais, que cada qual relaciona e tem de solucionar seus dilemas, desafios e problemas. Neste caso, deve-se frisar com firmeza e obstinação que o cosmopolitismo liberalizante da autorregulação, do livre trânsito de ideias e do desatrelamento do processo criativo junto às instituições estatais precisa ser mediado pelo papel atinente das instituições como receptáculos fomentadores de políticas e ações capazes de induzir, catalizar e promover a aplicação de soluções voltadas para as sempre específicas necessidades regionais. O extensionamento como dimensão e prática presume que esta criatividade tem propensão, potencial e condições para sair dos muros da Universidade, fazendo com que produtos e serviços que nasceram de projetos ou de iniciativas acadêmicas da Unifap cheguem à sociedade e seus usuários e clientes.

O caso de instituições públicas de educação e/ou de ciência e tecnologia, cuja expectativa da sociedade pelo retorno de so- 
luções, dispensa apresentações. Situar o dilema de gerir a inovação defronte aos problemas contemporâneos na cimeira do planejamento estratégico e no cerne do provimento de soluções faz com que a usual escolha de inovar ou não inovar conforme a ordem do dia e a demanda eventual seja um déficit estratégico, já que as oportunidades de novas técnicas surgindo para novos problemas permite englobar ao aperfeiçoamento do processo o provimento de soluções inovadoras para problemas das circunstâncias, necessidades ou contextos. Assim, reforça-se o papel estratégico a se desempenhar por cada ICT e IES como usina de ideias criativas, endogeneizantes na pesquisa ou exogeneizantes na extensão, na busca pela soberania e autonomia para a subsistência em um mundo tão globalizado e competitivo pode potencializar. Este papel pode-ser potencializado, na dimensão da transferência tecnológica, como expressão da importação de saberes como apropriação e decodificação, agregando valor como produção e aprimoramento decorrentes e, por fim, de exportação e reinserção.

Ou seja, diante das mudanças globais ofertadas à região no seu desafio cotidiano da inserção e subsistência regional, como a Universidade enquanto Instituição de Ciência e Tecnologia, mas também de Ensino Superior, pode se apropriar destas mudanças para se fortalecer em pesquisa e extensão.

\section{O NITT COMO UMA CONSTRUÇÃO INSTITUCIONAL E SUA MEMÓRIA}

A partir da constituição, em 2010, do Núcleo de Inovação e Transferência de Tecnologia da Universidade Federal do Amapá
(NITT/Unifap) e da progressiva implementação da sua missão institucional - "Promover a adequada proteção das invenções geradas no âmbito da Unifap e a sua transferência ao setor produtivo, visando integrar a Unifap com a comunidade e contribuir para o desenvolvimento cultural, tecnológico e social do país." - com a sua profunda integração com a Reitoria e a Pro-Reitoria de Pesquisa e Pós-Graduação (PROPESPG), resultados de expressão local e ineditismo foram alcançados no alvorecer dos 27 anos de Unifap. Foram diversas gestões e equipes que compuseram, em esforços como minicursos, projetos tecnológicos, prospecções e missões exploratórias em busca de conhecimento; e tais gestões e equipes devem ser reconhecidas e valorizadas na memorabilia institucional do desenvolvimento da inovação, ciência e tecnologia na Universidade.

Em 2016, um de seus anni mirabiles para a Inovação Tecnológica como pauta da Universidade, estes esforços integrados, somados ao forte ímpeto em superar o status quo ante dos coeficientes relativos - até então mantidos em zero - às formas reconhecidas de propriedade intelectual/industrial no Brasil pelo Instituto Nacional da Propriedade Industrial (INPI), realizaram-se os primeiros pedidos de proteção do que se constataram como factíveis protótipos no segmento de patentes e registros de programa de computador. Tal iniciativa, amplamente apoiada no legado das gestões anteriores a esta, e por sua vez tributária da iniciativa da Rede NAMOR / MCTIC - a rede de NITs da Amazônia Oriental, contando com ICTs do Pará, Amapá e Tocantins, liderada pelo Museu Paraense Emílio Goeldi (MPEG) -, gerou o pedido nacional de Invenção, Modelo de Utilidade, Certificado de 
Adição de Invenção de no. BR 102016 021728 8, de autoria dos drs. Geraldo Maranhão e Alaan Ubaiara Brito, com o apoio dos discentes Salatiel Guimarães Jr. e Andreza Costa, desbravando tal dimensão e constituindo o pioneiro pedido de patente da Universidade. Adjacente a isto, em temporalidade praticamente síncrona, foi solicitada em setembro de 2016 o pedido de registro de programa de computador BR 51 2016 001159-9 (FRACTRON), de autoria dos Drs. Rafael Pontes de Lima e Pedro Franco Sá, além da colaboração de José Luis Soares Batista. Este segundo, publicado na Revista da Propriedade Industrial (RPI) de 17/01/2017, com o deferimento do mesmo pedido, assegurou para a Universidade 0 regime de guarda diante do INPI até setembro de 2026 significando que o software resultado de um esforço que por sua vez integrou de forma exemplar ensino, pesquisa e extensão, conectando-se plenamente com a lógica da transferência de tecnologia para o beneficiamento social - fica protegido diante do nosso processo de registro e das instâncias devidas. Quanto às patentes, com notável dilatação no tempo de resposta do INPI se comparados aos programas de computador, pela complexidade da análise da anterioridade e originalidade, a expectativa do primeiro deferimento situa-se em médio/longo prazo ${ }^{1}$.

\footnotetext{
${ }^{1}$ No presente momento da redação deste texto, a Universidade Federal do Amapá tem outros seguintes depósitos de pedido de concessão de patente tramitando no Instituto Nacional da Propriedade Industrial (INPI). A saber: BR 1020170059910 (NANOEMULSÃO MISCÍVEL EM ÁGUA À BASE DE MISTURA DE DITERPENOS EM ÓLEO E SEU USO COMO LARVICIDA), invenção de Anna Eliza Maciel, Caio Pinho Fernandes, José Carlos Tavares Carvalho; BR 1020170010732 (SOLUÇÃO CORANTE COM EXTRATO ETANÓLICO PADRONIZADO DE BIXA ORELLANA L. (URUCUM) (SC-EEPU), SUA APLICAÇÃO NA COLORAÇÃO DE PAPANICOLAU, E SUAS MODIFICA-
}

É importante registrar que os desafios quanto aos primeiros registros de Propriedade Intelectual ainda estão longe de se encerrar. Se no que diz respeito a Registros de Marca e Localizações Geográficas ainda mantemos esta situação de zerado coeficiente, também se pode mencionar o enorme potencial, em especial nas áreas da saúde e das ciências exatas e tecnológicas, para tantas outras patentes e programas, podendo fazer da Unifap uma verdadeira usina de projetos, ideias, iniciativas e, por conseguinte, de inovação. Acreditamos na importância desta inovação, se conectada a uma governança participativa e ao empodeiramento das sociedades e povos regionais, para 0 integrador beneficiamento emancipatório da sociedade amapaense e amazônida. Frisa-se, nesta direção, que a transferência de tecnologia é uma preocupação premente do NITT desde um ponto de vista institucional, na medida em que retomamos o processo de institucionalização da Política de Inovação da Universidade - uma demanda antiga, cuja minuta ao Conselho Universitário foi proposta por anterior gestão - e também contribuímos para a constituição do reconhecimento formal e multilateral sobre as atividades empreendedoras de

ÇÕES), invenção de Edilson Leal da Cunha, Irlon Maciel Ferreira, José Carlos Tavares Carvalho; BR 102016 0217288 (DISPOSITIVO PARA PROGRAMAÇÃO DE CONTROLADORES E SEU USO EM CONVERSORES DE FREQUÊNCIA), invenção de Geraldo Neves de Albuquerque Maranhão, Alaan Ubaiara Brito, Salatiel Guimarães Júnior, Andreza Fernandes da Costa; BR 10 20170119351 (NANOPARTÍCULAS DE ÁCIDO ANACÁRDICO EXTRAÍDO DO CAJU E SEU USO COMO AGENTE BACTERICIDA E LARVICIDA), invenção de Francisco Fábio Oliveira de Sousa, Jennifer Thayanne Cavalcante de Araújo; e BR 2020170204826 (DESPOLPADEIRA FOTOVOLTAICA DE AÇAÍ), invenção de Alaan Ubaiara Brito, Allana Trajano Feijão, Anita Maria das Graças Almeida. 
empreendedorismo, ofertando minutas de resoluções a este mesmo Conselho sobre startups, incubadoras e empresas juniores que atuam dentro da Universidade.

Vale frisar, neste histórico sobre extensionamento, o papel de iniciativas pedagógicas que impactaram construtivamente na direção de um ecossistema de Inovação mais amplo, recenseado e inter-relacional. Destacamos o papel do NITT na adesão à Rede \#InovaAmapá - uma rede regional de núcleos de inovação e intervenientes no debate estadual, com franca ênfase na presença da governança estadual - e, em um segundo momento adjacente à este, a consecução da rotina da iniciativa \#InovaUnifap, baseada em dois nichos de atuação interdependentes e complementares: o primeiro, de programas de rádio geridos pelo NITT semanalmente; o segundo, a mala direta (newsletter) quinzenal de divulgação de notícias, editais, eventos e iniciativas de destaque regional, nacional e global. Compreendemos que, no âmbito das ações de organização reticularizante, típicas de interações interinstitucionais leves e ágeis, guardadas as proporções, a Rede \#InovaAmapá tem franca inspiração no trabalho, em escala mesorregional, da Rede NAMOR / MCTIC, considerando que sinergias perfiladas na diversidade, mas com interesses francamente comuns, poderiam gerar como assim avaliamos que o fora - uma interação complementar entre as ICTs e IESs regionais. Não poderíamos, neste mesmo sentido, ignorar o papel da iniciativa promovida pela Secretaria de Estado de Ciência e Tecnologia (SETEC/AP), por meio do Centro de Incubação de Empresas do Instituto de Pesquisas Científicas e Tecnológicas do Estado do Amapá (CIE/IEPA), em trazer maior articulação em meio a um e- cossistema tão diverso de intervenientes. 0 próximo passo, muito possivelmente, será a articulação interativa com os setores produtivos, de diferentes tamanhos e padrões, na direção da constituição de maiores laços cooperativos para que a transferência da tecnologia ocorra, com o devido impulsionar do poder público como corregente desta aceleração.

É importante frisar, de forma igualmente relevante, a movimentação do Governo do Estado do Amapá (GEA), por meio de sua Secretaria de Estado de Ciência e Tecnologia (SETEC/AP), para a promoção de um Marco de Ciência, Tecnologia e Inovação para o estado. A minuta, em exibição para toda a comunidade acadêmica, setores produtivos e sociedade civil desde novembro de 2017, deverá ser revisada pela cidadania ao longo dos meses a seguir, com o horizonte de conclusão do processo para o mês de Fevereiro de 2018, em previsão ${ }^{2}$.

Ainda nesta dimensão de relações reticulares, o NITT também vem buscando, ao longo dos últimos meses e anos, a adesão da Unifap à rede PROFNIT - Programa de Pós-Graduação em Propriedade Intelectual e Transferência de Tecnologia para a Inovação, gerido pelo Fórum Nacional de Gestores de Inovação e Transferência de Tecnologia (FORTEC) ${ }^{3}$ - neste momento tramitando-se proposta, buscando intervir de

\footnotetext{
2 SANTOS, Eloisy. Governo lança minuta do Marco Legal da Ciência, Tecnologia e Inovação do Amapá. Disponível em: <https://www.portal.ap.gov.br/noticia/2311/ governo-lanca-minuta-do-marco-legal-da-ciencia-tecno logia-e-inovacao-do-amapa>. Acesso em 29 nov 2017.

${ }^{3}$ A direção atual do NITT / Unifap colabora, diante do FORTEC, como parte da atual gestão regional Norte do Fórum, como vice-coordenação, em representação aos estados do Acre, Amapá, Amazonas, Pará, Rondonia, Roraima e Tocantins, até o período da transição para uma nova gestão em maio de 2018.
} 
forma associada em ensino e pesquisa por meio da atuação no âmbito da pósgraduação stricto sensu no Amapá. Há, por último, um sem-número de ações, ainda em estruturação e em busca de convergência estrutural, com ICTs e IESs regionais do Amapá e estados vizinhos, frisando-se especialmente as ações ligadas ao CIE/IEPA, e ao pool de colaboradores que contam com parceiros importantes: a Universidade Estadual do Amapá (UEAP), o Instituto Federal do Amapá (IFAP), o Serviço Brasileiro de Apoio às Micro e Pequenas Empresas no Amapá (SEBRAE/AP), que se reúnem sistematicamente durante a realização alternada da anual Semana Nacional de Ciência e Tecnologia (SNCT) e em outros momentos propícios.

Considerando a imediata premissa da transferência da tecnologia produzida nesta Unifap que não apenas é uma Instituição de Ciência e Tecnologia (ICT), mas também uma Instituição de Ensino Superior (IES) temos ampla capacidade de realizar o duplo exercício de concertação de agendas de pesquisa integradas com o mais plural interesse social, por um lado, sem deixar de lado a interação com o poder público e as forças produtivas, por outro, garantindo assim a sustentabilidade como força motriz da emancipação por meio dos pilares da amálgama entre ICT e IES: a educação e o desenvolvimento científico-tecnológico da região como objetivos. Neste cenário esperançoso e progressivamente entusiasmante, o NITT vem conseguindo superar tais inércias em termos de coeficiente e promovendo, assim, a elevação dos seus próprios padrões. Tais esforços - produção, registro e obtenção do registro, e depois de sua proteção, a transferência socioeconomicamente concertada e sustentável - são parte es- sencial do trabalho da Unifap na garantia da qualidade, da soberania e da implementação da sua produção intelectual e industrial diante dos órgãos de competência. Os esforços na pesquisa e no desenvolvimento também se deslocam, na atual gestão da Universidade, para o fortalecimento e adensamento de pedidos de concessão de patente para invenções e modelos de utilidade, visando à melhoria quantitativa e qualitativa dos coeficientes da nossa pesquisa científica em todos os segmentos para a transformação e evolução do ambiente acadêmico da Unifap.

Mesmo com o que reconhecemos como fundamental nesta jornada desbravadora todo o apoio institucional e a força de trabalho historicamente instalada no NITT, criativa e comprometida -, ainda dispomos de uma estrutura simples e precária diante das nossas necessidades, prevendo um/a (1) técnico/a administrativo/a, um/a (1) diretor/a indicado pela Reitoria e ProReitoria e três (3) coordenadores/as de área indicados pela Direção, contando com auxílio prático de bolsistas de extensão e iniciação científica para o amparo das atividades. Temos a ousadia em expressar que, para o que se considera potencialmente factível em uma Universidade promissora como a Unifap, localizada em um estado e em uma macrorregião tão ricas, aguerridas e plurais como o Amapá e a Amazônia brasileira, é possível falar que podemos fazer muito mais. Nessa mesma direção, consideramos importante frisar que o contexto institucional brasileiro sobre Inovação, Tecnologia e suas produções e transferências vem mudando sensivelmente.

\section{HORIZONTES DE ATUAÇÃO PARA A GES-} TÃO DA INOVAÇÃO E TRANSFERÊNCIA DE 
TECNOLOGIA EM UMA ICT AMAZÔNICA, PERIFÉRICA E TARDIA

No que consiste, então, nossa intervenção e proposta de mudança estrutural de Núcleo de Inovação para Agência de Inovação? Considere-se, à titulo de interlocução e propositura, que esta é a experiência primordial a qual nos debruçamos neste momento como protótipo para a elevação das condições verticais e horizontais da Inovação na Universidade Federal do Amapá.

Observando o amplo leque de mudanças em estudo a guisa do aprimoramento das atividades institucionais seguindo as melhores práticas de governança, para torna-las mais eficientes e também (no nosso contexto específico enquanto ICT e IES) para acompanhar o constante progresso e transições produtivas em um contexto de mudanças tecnológicas e sociais profundas, o NITT estuda as melhores formas de dar vazão e ter institucionalmente - e, por conseguinte, de forma perene - instaladas as mais sofisticadas, potentes e estratégicas disposições, instrumentos e dinâmicas para o desenvolvimento deste nosso duplo papel na ciência e na educação. Assim, não obstante constatada a Lei no $10.973^{4}$, de 2004, que tornou-se histórica como a nossa "Lei de Inovação", instalando diversos dispositivos e normativas sobre as Instituições. No nosso caso, seu art. 16 impõe e aponta as diretrizes para o papel dos Núcleos de Inovação Tecnológica - os 'NITs' - que, a rigor, possuíam as seis atribuições originais (ou-

\footnotetext{
${ }^{4}$ BRASIL. Lei 10.973.. Dispõe sobre incentivos à inovação e à pesquisa científica e tecnológica no ambiente produtivo e dá outras providências. Disponível em: <http://www.planalto.gov.br/ccivil_03/_ato20042006/2004/lei//10.973.htm>, de 2 de dezembro de 2004. Acesso em 28 out 2017.
}

tras quatro foram incluídas pelo Marco Civil de Ciência, Tecnologia e Inovação, a Lei no 13.243 de $2016{ }^{5}$ ), consagrando a sua importância no Sistema Nacional de Inovação.

Apesar de se reconhecer impreterivelmente a importância dos NITs e do que a Lei de Inovação contribuiu para a constituição contemporânea de nossa matriz nacional de produção científica inovadora, o Marco Civil de 2016 por sua vez contribuiu substancialmente para a modernização, desburocratizante e liberalizante, deste sistema. Constata-se que cresceu de importância a necessidade de mão de obra especializada para realizar prospecção tecnológica e inteligência competitiva, e que estudar cenários futuros e vislumbrar possíveis nichos de atuação e mudanças de trajetória tecnológica são tarefas que demandam profissionais habilitados em cada setor que a ICT pretende introduzir produtos ou processos.

Partindo de duas premissas centrais, a. A aprendizagem institucional e tecnológica, bem como a capacidade de inovar baseando-se no conhecimento científico, consolidam as atuais ferramentas do progresso técnico e da geração de riqueza, e b. A articulação público-privado passou a ser a alavanca dos Sistemas de C,T\&I (Leis de incen-

\footnotetext{
${ }^{5}$ BRASIL. Lei 13.243. Dispõe sobre estímulos ao desenvolvimento científico, à pesquisa, à capacitação científica e tecnológica e à inovação e altera a Lei no 10.973, de 2 de dezembro de 2004 , a Lei no 6.815 , de 19 de agosto de 1980, a Lei no 8.666, de 21 de junho de 1993, a Lei no 12.462 , de 4 de agosto de 2011, a Lei no 8.745 , de 9 de dezembro de 1993, a Lei no 8.958 , de 20 de dezembro de 1994, a Lei no 8.010, de 29 de março de 1990, a Lei no 8.032 , de 12 de abril de 1990, e a Lei no 12.772 , de 28 de dezembro de 2012, nos termos da Emenda Constitucional no 85, de 26 de fevereiro de 2015. Disponível em: <http://www.planalto.gov.br/ccivil_03/_ ato2015-2018/2016/lei/l13243.htm>. 11 de janeiro de 2016. Acesso em 28 out 2017.
} 
tivos e Fundos Públicos), os NITs ganham novo significado neste cenário. Abrem-se oportunidades para a contratação de pessoal através de contrato administrativo por tempo determinado com característica excepcional para pesquisa - ou seja, as ICTs podem captar profissionais ou contratos de serviço para pesquisa. Além disso, o Marco Civil, entre outras mudanças e reconfigurações, promove regime diferenciado (lógica da RDC) para pesquisadores, técnicos e tecnólogos e destrava burocracias da Lei 8.666 para fins de pesquisa e desenvolvimento; Simplifica regras e reduz impostos para importação de material de pesquisa; Permite que docentes/pesquisadores de ICTs públicas em DE exerçam atividade de pesquisa também no setor privado, com remuneração e aumenta o número de horas para atividades fora da universidade, de 120 horas para 416 horas anuais (8 horas/semana); ICTs podem compartilhar uso de laboratórios e equipes com empresas, para fins de pesquisa, desde que não cause conflito; Permite que as empresas envolvidas nesses projetos mantenham a propriedade intelectual sobre os resultados (produtos) das pesquisas; Desembaraça problemas aduaneiros de produtos de CTI, buscando acelerar as pesquisas e diminuir custos administrativos; Permite remanejamento dos recursos orçamentários de CTI entre categorias de programação sem necessidade de nova autorização legislativa; Permite que bens adquiridos com financiamentos externos sejam incorporados ao patrimônio da entidade de ICT; Garante ao servidor afastado para o exercício de atividade de CTI, das mesmas vantagens e benefícios que teria se estivesse em efetivo exercício; Permite de internacionalização das ICT mediante acordos de cooperação, especialmente pela e- xecução de atividades e alocação de recursos humanos no exterior. Dentro das ICTs, não apenas as próprias como seus NITs podem agora ser constituídas como entes públicos ou pessoas jurídicas de direito privado sem fins lucrativos (Lei 10.973/04): nada impede que NITs obtenham personalidade jurídica própria, como fundação de apoio, com a finalidade de captar, gerir e fomentar tecnologia e inovação aplicadas. Assim, não apenas a sua estrutura seria capaz de angariar recursos e gerir recursos como Fundação - algo que é caro em um ecossistema emergente como o amapaense - para a ICT/IES, mas também para operar com seu próprio overhead administrativo e induzir agendas de pesquisa potencialmente transferíveis para estimular o mercado, mas também fazer o papel inverso: ir ao meio empreendedor e ofertar serviços que a Universidade pode prestar por meio de cooperação. Sua personalidade jurídica própria permitiria tal mobilidade dentro das prerrogativas estabelecidas para os 'pós-NITs' no Marco Civil.

Diversos exemplos apontam no mais alto padrão de excelência brasileiro para ações convergentes em agências de Inovação. Regionalmente, citaríamos o caso da Universidade Federal do Oeste do Pará (UFOPA) ${ }^{6}$, com disposições atualizadas, e nacionalmente o caso da Universidade Estadual de Campinas (UNICAMP) ${ }^{7}$, que é exemplo costumeiramente utilizado como modelo.

Do ponto de vista estrutural, a reforma do NITT para conversão em AIT promoveria mudanças sensíveis no sentido da ampliação da sua participativa governança, ao propor um Conselho Gestor, representativo

\footnotetext{
${ }^{6}$ Ver http://www.ufopa.edu.br/institucional/suplemen tares/agencia-de-inovacao-tecnologica-ait

${ }^{7}$ Ver http://www.inova.unicamp.br/sobre-a-inova/
} 
das Pro-Reitorias e dos Departamentos, que trabalharia lado-a-lado com a Direção e mediariam suas ações e decisões; adequaria a sua dinâmica burocrático-administrativa a uma lógica mais perene e estabilizada, ao substituir a transitoriedade das Coordenações de Área - atualmente indicadas - por Secretarias, que não alternam no movimento de assunção de cada gestão e teriam caráter técnico, altamente especializado $\mathrm{e}$ integralmente concentrado no NITT, sem compartilhamento das horas de atividade na ICT/IES; canaliza a atividade de pesquisa para uma dimensão livre e menos atrelada às disposições e estímulos das Coordenações, neuralizando-as por meio de uma rede espontânea ou induzida de Agentes da Inovação na Universidade, papel que pode ser apropriado por qualquer discente, técnico ou docente da Unifap na direção de capilarizar a pesquisa e ser alvo de estímulos como editais, chamadas e premiações, ou até mesmo contratações.

Tais mudanças promoveriam, na prática, o envolvimento da AIT com diversas atribuições factíveis e com franco potencial para o desenvolvimento e a captação de projetos na ICT/IES, como por exemplo: Construção de agendas de pesquisa e transferência de tecnologia socialmente conectadas, gerando soluções palpáveis e sustentáveis; Gestão top-down e bottom-up de projetos, proporcionando a oportunização e empodeiramento multilateral da comunidade científica; Apoio às atividades acadêmicas para a disseminação da cultura da Inovação, do Empreendedorismo e da Transferência de Conhecimento e Tecnologia; Articulação com empresas, incubadoras, ICTs e poder público para elaboração de projetos e captação de recursos; Cooperação com Departamentos de Extensão e Pesquisa para ma- peamento de projetos.

Inevitavelmente, tal horizonte de trabaIhos pode gerar, de forma frutífera, plural e capilarizante, a eclosão multiplicativa de startups, empresas juniores e suas federações, escritórios modelo e spin-offs / spinouts como modelagens de experimentos pro-transferência do conhecimento na Instituição, abrangendo a perspectiva de que a Hélice Tríplice pode ser agregada, em uma realidade específica como tal, por um processo de empoderamento amplo e plural, que envolva a sociedade organizada como uma quarta 'pá' neste processo de construção de um ciclo virtuoso em espiral. O panorama de um progressivo processo de reconstrução do papel das instituições públicas e privadas contemporâneas, à luz da Quarta Revolução Industrial e da digitalização dos processos decisórios, impõe tal condição para os sistemas de participação e representação em rede, ainda que facultada a cada temporalidade, espacialidade e cultura institucional. O condicionamento da construção de arranjos inovadores depende, assim, cada vez mais reciprocidade candente da interpenetração entre sociedade organizada, núcleos e agências institucionais e os diversos modelos de célula, organismo, estrutura ou cadeia produtiva. Em realidades pré ou pós industriais - e estamos neste segundo caso - tais nuances se acentuam, redimensionando padrões.

\section{A GUISA DE CONCLUSÃO - OU PARA ONDE PODEMOS CAMINHAR}

Caracterizando-se este contexto, entende-se que por meio desta atuação institucional a Universidade pode promover, com vistas ao melhor e mais aplicável modelo de intervenção junto ao seu complexo e vasto 
tecido social, o livre trânsito do público e espontânea inscrição de propostas inovadoras de pesquisa, ainda que se considere mister a indução à pesquisa por parte de atores seccionais de interesse estratégico a serem acionados. Estes, por sua vez, teriam o compromisso interdependente da exposição de soluções voltadas para as sempre específicas necessidades regionais por meio de oficinas preparatórias e vitrines como prévia e cultivo de propostas inovadoras. Tais ações, como diretrizes, potencializariam a atração em receber iniciativas livres (inclusive as doravante publicamente reconhecidas como startups) sem custos e com prerrogativa de capacitá-las, aprimorá-las e validá-las ${ }^{8}$, para que assim se premiassem e incubassem as melhores propostas que sejam voltadas para dois modelos básicos e gerais de aplicação possível no ambiente da Unifap, sempre voltados para a melhoria dos serviços, processos ou produtos da Universidade: $a$. softwares/aplicativos e $b$. modelos de utilidade, como têm sido o foco até então desta atuação.

Assim sendo, em linhas gerais a Unifap se encarregaria em promover o seu papel como agência para o desenvolvimento regional, socialmente referenciada por meio de um conjunto de atores específicos da instituição, em coordenação com inventores e autores capazes de serem acionados internamente por estímulo desta Agência, com intervenções induzidas pela PROPESPG e Pro-Reitoria de Extensão e Ações Comunitárias (PROEAC), podendo receber membros representantes do pool de colaboradores

\footnotetext{
${ }^{8}$ As primeiras experiências relativas à validação de startups as quais esta gestão do NITT tem notícia, no âmbito da Unifap, circunscrevem-se no ambiente do Curso de Administração de Empresas, em iniciativa conduzidas pelo prof. Claudio Marcio de Mendonça.
}

que contam com parceiros importantes: a Universidade Estadual do Amapá (UEAP), o Instituto Federal do Amapá (IFAP), o Serviço Brasileiro de Apoio às Micro e Pequenas Empresas no Amapá (SEBRAE/AP), o Instituto de Pesquisas Cientificas e Tecnológicas do Estado do Amapá (IEPA), por exemplo) a selecionar as propostas iminentemente aptas a participar e receber nossa assistência. Tais interlocutores, por sua vez, poderiam exercitar um espaço compartilhado de benchmark - possivelmente coordenado pela Secretaria de Estado de Ciência e Tecnologia - para a construção de interações procompartilhamento e, com a devida estruturação, em soluções conjuntas.

Especulando sobre as potencialidades e expertises em instalação para prestar tal assistência, especialistas (seniores ou juniores), doravante reconhecidos como 'mentores' pelo seu destacado conhecimento específico e singular em áreas diversas como programação computacional, preparo e validação de modelos de negócio, branding e propaganda, orçamento e gestão de recursos, engenharias e sistemas complexos, entre tantas outras utilidades necessárias para o desenvolvimento poderiam dispor da sua expertise (por sua vez já instalados na Unifap nos já correntes Laboratórios, Departamentos, Núcleos, Cursos e Projetos, bem como nas ICTs e IESs parceiras, que podem e devem ser chamadas a colaborar) para intercambiar conhecimentos úteis para o desenvolvimento de tais startups através de oficinas que ocorreriam eventualmente em um cenário prospectivo onde a Transferência da Tecnologia é, inevitavelmente, a próxima fronteira a se romper.

Acreditamos na importância desta inovação, se conectada a uma governança participativa e ao empodeiramento das socieda- 
des e povos regionais, para o integrador beneficiamento emancipatório da sociedade amapaense e amazônida. Frisa-se, nesta direção, que a transferência de tecnologia é uma preocupação premente do NITT desde um ponto de vista institucional ligado à PROPESPG como atividade-meio, na medida em que retomamos o processo de institucionalização da Política de Inovação da Universidade - uma demanda antiga, cuja minuta ao Conselho Universitário foi proposta por anterior gestão - e também contribuímos para a constituição do reconhecimento formal e multilateral sobre as atividades empreendedoras de empreendedorismo, ofertando minutas de resoluções a este mesmo Conselho sobre startups, incubadoras e empresas juniores que atuam dentro da Universidade. Como atividade-fim, pondera-se, a contribuição da PROEAC seria de importante contributo tendo em vista a natureza dialógica do processo de transferência com o extra-muros da Universidade.

Consideramos essencial a imediata premissa da transferência da tecnologia produzida nesta Unifap que não apenas é uma Instituição de Ciência e Tecnologia (ICT), mas também uma Instituição de Ensino Superior (IES), como acima referenciado. Assim, temos ampla capacidade de realizar o duplo exercício de concertação de agendas de pesquisa integradas com o mais plural interesse social, por um lado, sem deixar de lado a interação com o poder público e as forças produtivas, por outro, garantindo assim a sustentabilidade como força motriz da emancipação por meio dos pilares da amálgama entre ICT e IES: a educação e o desenvolvimento científico-tecnológico da região como objetivos inabaláveis. No aprimoramento desta dimensão da transferência e do incremento da participação, defendemos o argumento de que uma feira de inovação pode ser um formato célere, objetivo e instrumental para a mobilização de soluções criativas voltadas para o desenvolvimento da Universidade e da região utilizando o máximo potencial de todas as suas divisões, departamentos e cursos de forma plena, sistemática e multilateral.

\section{BIBLIOGRAFIA}

ARBIX, Glauco. Estratégias de inovação para o desenvolvimento. Tempo Social, revista de sociologia da USP, v. 22, n. 2. Disponível em: <www.scielo.br/pdf/ts/v22n2/v22n2a 09.pdf>. Acesso em 12 jan 2017

BRESSER-PEREIRA, Luiz Carlos. O conceito histórico de desenvolvimento econômico. Trabalho originalmente preparado para curso de desenvolvimento econômico na Fundação Getúlio Vargas. Versão de 2 de março de 2006. Disponível em: <www.bres serpereira.org.br/papers/2006/06.7-concei tohistoricodesenvolvimento.pdf>. Acesso em 09 jan 2017.

CASTELLS, Manuel. Prólogo: A rede e o Ser. In: A sociedade em rede. São Paulo: Paz e Terra, 1999. Disponível em: <https: //edisciplinas.usp.br/pluginfile.php/392264 /mod_resource/content/1/C astells $>$. Acesso em 09 jan 2017.

CHANG, Ha-Joon. Patada a la escalera. Trabajo presentado en la conferencia sobre "Globalisation and the Myth of Free Trade" ("La mundialización y el mito del libre comercio») celebrada en la New School University de Nueva York, el 18 de abril del 2003. Traducción al castellano de José A. Tapia. Disponível em: <http://www.rebeli on.org/docs/6790.pdf>. Acesso em 09 jan 2017.

CHRISTENSEN, C., RAYNOR, M. \& 
McDONALD, R. What is Disruptive Innovation? Harvard Business Review, Dez 2015. Disponível em: <http://www.ey.com/Publication /vwLUAssets/ey-hbr-disruptive-innovation/ \%24FILE/ey-hbr-disruptive-innovation.pdf>. Acesso em 10 jan 2017.

ETZKOWITZ, Henry \& ZHOU, Chunyan. Hélice Tríplice: inovação e empreendedorismo universidade-indústria-governo. Estudos Avançados, n. 90, v. 31, 2017

RABELLO, Antonio Claudio. Amazônia: uma fronteira volátil. Estudos Avançados, v. 27, n. 78, 2013. Disponível em: <www.scielo.br/ pdf/ea/v27n78/14.pdf>. Acesso em 14 jan 2017.

SANTOS, Marli Elizabeth Ritter dos, TOLEDO, Patricia Tavares Magalhães de \& LOTUFO, Roberto de Alencar (orgs). Transferência de Tecnologia: estratégias para a estruturação e gestão de Núcleos de Inovação Tecnológica. Campinas, SP: Komedi, 2009.

STAUB, Eugênio. Desafios estratégicos em Ciência, Tecnologia e Inovação. Conferência Nacional de Ciência, Tecnologia e Inovação, Ministério da Ciência e Tecnologia, Academia Brasileira de Ciências. Brasília, 18 a 21 de setembro de 2001. Disponível em: $<$ www.iedi.org.br/admin_ori/pdf/desafios.p df>. Acesso em 09 jan 2017.

Artigo recebido em 29 de novembro de 2017.

Aprovado em 29 de novembro de 2017. 